\title{
O fim dA ANTROPOLOGIA
}

\author{
A INVENÇÃO DA CULTURA \\ de Roy Wagner. Trad. Marcela Coelho de Souza e Alexandre Morales. São Paulo: Cosac Naify, 2010. 253 pp.
}

MARCIO GOLDMAN

[1] A interpretação das culturas foi traduzido para cerca de vinte línguas; Cultura e razão prática foi traduzido ao menos para o alemão, espanhol, francês, italiano e português. Mas $A$ invenção da cultura é a primeira tradução do livro de Wagner. Além disso, o livro praticamente não foi resenhado ao ser publicado. Duas exceções cuja incompreensão e má vontade para com o autor fazem beirar o ridículo — são: Beattie. J. "Roy Wagner: the invention of culture". Rain, vol.13, 1976, p. 10; e Blacking, J. "Wagner, Roy. The invention of culture". Man, vol. 11, $\mathrm{n}^{\circ} \cdot 4$, New Series, 1976 , pp. 607-8.
Há três modos de abordar $A$ invenção da cultura: enfatizar a originalidade quase absoluta do livro, seu caráter intempestivo; inventariar suas dívidas para com os autores a ele contemporâneos ou para com aqueles de um passado recente ou remoto; tentar, enfim, um equilíbrio judicioso entre a primeira e a segunda opções. Por diversas razões escolhi deliberadamente a primeira alternativa.

Deste ponto de vista, poderíamos observar inicialmente que a primeira edição de $A$ invenção da cultura, em 1975, é quase simultânea a de dois outros livros de antropólogos norte-americanos que marcaram a antropologia contemporânea: $A$ interpretação das culturas, de Clifford Geertz, e Cultura e razão prática, de Marshall Sahlins - publicados, respectivamente, em 1973 e 1976. O destino desses três livros, contudo, continua sendo muito diferente. Afinal, os dois últimos conheceram uma difusão e um sucesso que o primeiro mal começa a experimentar e que dificilmente terá em grau comparável. No Brasil, por exemplo, o livro de Geertz foi traduzido, ainda que parcialmente, em 1978, e o de Sahlins em 1979'. E até hojeé raro encontrar um programa de curso de teoria antropológica que não os inclua na bibliografia.

A invenção da cultura, por outro lado, teve que esperar 35 anos para receber sua tradução, em ótima iniciativa da editora Cosac Naifye belo trabalho de tradução de Marcela Coelho de Souza eAlexandre Morales. Com efeito, é quase inevitável especular sobre qual teria sido o destino da antropologia brasileira se o livro de Wagner tivesse sido traduzido ainda na década de 1970 e os outros dois não. Talvez não estivéssemos ensinando uma antropologia tão afastada do que efetivamente se faz na disciplina hoje em dia; talvez tivéssemos resistido melhor ao imperialismo das análises construcionistas ou desconstrucionistas que apelam para o eterno poder e as inevitáveis manipulações ocultas atrás de qualquer situação; talvez nada tivesse acontecido... De toda 
forma, o que não é fácil imaginar é a tradução dos livros de Geertz e Sahlins 35 anos depois de terem sido originalmente publicados.

A "mensagem" desses livros parece tão adaptada ao momento em que foram escritos queé difícil concebê-los em outro contexto qualquer. Afinal, nos dois casos se tratava, em breves palavras, de salvar o culturalismo daquilo que sempre foi o que poderíamos chamar seu melhor inimigo, a saber, o reducionismo naturalista. Ou seja, aquilo sem o que a antropologia cultural simplesmente não pode funcionar, na medida em que lhe faltaria esse seu "outro", aquele que define, equivocadamente sem dúvida, o que a cultura elabora, interpreta, simboliza ou transcende - a natureza.

Observemos também, ainda que de passagem, que esse naturalismo se apresentava, tanto a Geertz como a Sahlins, sob uma dupla forma. De um lado, as antropologias ditas ecológicas ou materialistas, que ambos simplesmente recusam; de outro, uma versão muito mais complicada, sofisticada e, talvez, inesperada, o estruturalismo levistraussiano. Afinal, apenas dois anos antes da publicação do livro de Geertz, Lévi-Strauss havia concluído sua mitológica tetralogia - em que a demonstração da incrível sofisticação de que era capaz o pensamento indígena parecia anular qualquer possibilidade de redução - com um livro significativamente intitulado O homem nu, que conclui com a peremptória afirmativa de que, no final das contas, tudo não passa do produto da atividade do cérebro humano, ele mesmo produto de um complexo processo de evolução natural: higher naturalism ${ }^{2}$, como definiu Sahlins; hypermodern intellectualism, nas palavras de Geertz3. Mas, se Geertz parece simplesmente recusar a alternativa levistraussiana buscando refúgio numa hermenêutica que invariavelmente funciona como saída sofisticada para os que não gostam da noção de estrutura, a reação de Sahlins é diferente. Oriundo, ele próprio, de uma tradição antropológica materialista e neoevolucionista, um estágio em Paris o fez imaginar a possibilidade de, por assim dizer, embutir o estruturalismo no culturalismo, fazendo das "estruturas da mente" os "instrumentos da cultura", não sua "condição"4, e da própria estrutura apenas uma parte da cultura e da história.

O livro de Wagner segue um caminho bem diferente, seja em relação ao interpretativismo geertziano, seja em face do culturalismo estruturalizado de Sahlins. Tão diferente que podemos ter hoje a sensação de que não são apenas um ou dois anos para mais ou para menos que separam $A$ invenção da cultura desses dois outros livros, mas algo como meio século! De fato, se $A$ interpretação das culturas e Cultura e razão prática soam hoje como anúncio do fim (no duplo sentido de acabamento e de término) de uma antropologiafin de siècle (século xx), A Invenção da cultura parece anunciar o início de outra coisa, que pode-

\footnotetext{
[2] Sahlins, M. Culture and practical reason. Chicago: The University of Chicago Press, 1976, p. 121.

[3] Geertz, C. The interpretation of cultures. Nova York: Basic Books, 1973, p. 359.
}

[4] Sahlins, op.cit., pp. 122-3. 
[5] Como escreveu com humor James Wafer, podemos ter saudades "do paraíso perdido da antropologia, quando era possível distinguir um tique de uma piscadela, e piscadelas reais daquelas de brincadeira" (The taste of blood: spirit possession in Brazilian candomblé. Philadelphia: University of Pennsylvania Press, 1991, p. 117). ríamos imaginar como uma das possibilidades abertas para a antropologia do século XXI.

A esse respeito, talvez valha a pena observar que os leitmotifs centrais das obras de Geertz e Sahlins - a interpretação e a simbolização, respectivamente - não deixam de ser evocados por Wagner, ainda que para preparar outras reflexões. Assim, desde o início do livro, a "interpretação" aparece na forma da "moderna cultura interpretativa americana" (p. 10), tema que será desenvolvido no item "A magia da propaganda" (pp. 107-19) do capítulo 3 de modo evidentemente bem distinto daquele de Geertz. Pois aquilo que este trata como um dispositivo metodológico que apenas prolonga e torna mais sofisticado um procedimento inerente a qualquer cultura humana (a "interpretação", justamente) será analisado por Wagner como uma singularidade de uma cultura particular, a "norte-americana". Em termos mais precisos, pode bem ser que a interpretação seja um modo universal de lidar com o mundo e com a sociedade, mas o problema é que essa generalidade não nos diz nada sobre seu funcionamento em situações concretas e específicas. Isso significa, claro, que ela pode perfeitamente operar de acordo com a mecânica básica dos dispositivos chamados etnocêntricos: implementar como universal aquilo que é uma característica particular da cultura do próprio antropólogo. Neste caso, como insiste Wagner, tentando tornar cada vez mais transparente o caráter convencional da cultura em que vivemos. Ou, o que dá no mesmo, fomentando o desejo de nos tornarmos autoconscientes daquilo que, não obstante, sustentamos que nos determina. $\mathrm{Na}$ antropologia, sabemos bem onde tudo isso foi parar, na nossa versão particular do "pós-modernismo", e não é casual que tenham sido alunos ou discípulos infiéis de Geertz os que lançaram a moda entre nós5.

Antes de nos determos um pouco no chamado pós-modernismo antropológico, contudo, observemos que também a oposição entre "razão prática" e "razão cultural", que estrutura o livro de Sahlins, é de algum modo retomada em $A$ invenção da cultura. No entanto, ao contrário do estilo épico de Sahlins, que opõe as duas razões quase como o diabo ao bom deus, Wagner sublinha o fato de que as duas variedades de antropologia derivadas dessa oposição compartilham um mesmo solo ou, ao menos, uma necessidade comum. Pois se as antropologias naturalistas ou naturalizantes (analisadas no item "Controlando a cultura", pp. 214-20, cap. 6) atribuem uma ordem tão determinada e tão determinante à natureza, o efeito (a "contra-invenção") dessa atribuição é estabelecer um rigoroso controle sobre a cultura, eliminando tudo o que esta pode ter de criativo e indeterminado. Por outro lado (como exposto no item "Controlando a natureza", pp. 221 -29, cap. 6), mas de modo simétrico, as antropologias culturalistas (e nada impede que as duas variedades possam coexistir em doses variáveis) 
atribuirão todo ou quase todo poder de determinação à cultura, de tal forma que o controle incidirá agora do lado da natureza, cujo poder e indeterminação poderão aparecer doravante como meros limites da própria cultura.

Nem interpretação, nem simbolização, o conceito central do livro de Wagner, claro, é o de invenção. Mas neste ponto é preciso ter cautela. Como observa Martin Holbraad, na ótima "orelha" escrita para a edição brasileira, o termo "invenção" tem o mau hábito de despertar uma série de associações de ideias, todas igualmente inadequadas para a compreensão correta do sentido do conceito wagneriano.Grosso modo, podemos dizer que, ao ouvir a palavra "invenção", somos quase invariável e inevitavelmente conduzidos a noções como a de "artifício", no mau sentido da palavra, ou seja, como aquilo que é "artificial" e se opõe ao "real". Na definição do dicionário Houaiss, "invenção" é "coisa imaginada que se dá como verdadeira; invencionice, fantasia"; "coisa imaginada de modo astucioso, frequentemente com objetivos escusos"; ou "o que não pertence ao mundo real; imaginação, fábula, ficção, engano". Claro que também é "imaginação produtiva ou criadora, capacidade criativa; inventividade, inventiva"; e "faculdade de criar, de conceber algo novo ou de pôr em prática, de executar uma ideia, uma concepção; criação".

Por razões que próprio Wagner esclarece, os antropólogos parecem preferir as definições negativas às positivas. Assim, quando se fala na "invenção das tradições", imagina-se imediatamente que estas são "falsas", no sentido de não corresponderem à história que contam de si mesmas, e que certamente foram engendradas por alguém com objetivos pouco confessáveis. Talvez seja por isso que no curto post scriptum que escreveu para a edição brasileira, Wagner observe, de forma curiosa, que "em certo sentido, a invenção não é absolutamente um processo inventivo, mas um processo de obviação" (p. 240). Pois se em 1975 ou 1981 não era possível imaginar a direção que a compreensão da noção de invenção tomaria, em 2010 sabemos exatamente como as coisas se passaram. E isso ainda que $A$ invenção da cultura chame a atenção para o fato de que as "tradições são tão dependentes de contínua reinvenção quanto as idiossincrasias, detalhes e cacoetes" (p. 94). O que significa que "invenção" e "inovação" não são a mesma coisa (p. 77) que toda tradição é inventada e que, em uma expressão como "invenção das tradições", o primeiro termo (processo de invenção) deveria ser muito mais importante do que o segundo (o que acabou sendo inventado).

Adiante veremos como liberar a noção de invenção de seu estatuto crítico. Mas, antes, se vale a pena distinguir com clareza o pensamento de Roy Wagner daquele dos mais importantes antropólogos norte-americanos mais ou menos a ele contemporâneos ${ }^{6}$, isso
[6] Naverdade, tanto Geertz (nascido em 1926 e falecido em 2006) como Sahlins (nascido em 1930) são seniores em relação a Wagner, que nasceu em 1938. 
[7] Clifford, James e Marcus, George (orgs.). Writing culture: the poetics and politics of ethnography. Berkeley: University of California Press, 1986, p. 2.

[8] Achebe, Chinua. Home and exile. Nova York,Anchor Books, 2000, p.33.

[9] Como escreveu Michel Foucault, "a antropologia se enraíza, com efeito, numa possibilidade que pertence exclusivamenteà história de nossa cultura, mais ainda, a sua relação fundamental com toda a história, e que lhe permite ligar-se às outras sociedades sob o modo da pura teoria" (Les mots et les choses: une archéologie des sciences humaines. Paris: PUF, 1966, p.388). também é verdade em relação àquilo que se seguiu à publicação de A invenção da cultura na antropologia norte-americana. Como se sabe, esta tem a fama de ter passado por uma profunda revolução a partir de meados da década de 1980, quando a publicação de Writing culture anunciou o advento do pós-modernismo na antropologia. Salvo engano, $A$ invenção da cultura é citado apenas uma vez nesse livro, logo na "Introdução", de James Clifford7. E o é justamente, e apenas, para opor a noção de "invenção" à de "representação" — ou seja, para ilustrar o ponto central de Writing culture, o de que as etnografias que os antropólogos escrevem são obras de ficção, não representações da realidade.É o sentido crítico da noção de invenção que opera, só que agora dotado de uma aparente positividade que não possuía.

De todo modo, não se trata aqui de tentar ressuscitar os mortos, nem o pós-modernismo antropológico, nem as críticas tradicionais que a ele foram dirigidas. Um quarto de século depois, creio que o melhor que se pode dizer dos chamados pós-modernos é que foram capazes de levantar algumas questões realmente importantes, ainda que não tenham oferecido respostas interessantes para nenhuma delas! Isso provavelmente porque seus objetivos nunca foram os de responder ao que quer que fosse, mas, como se dizia, de adotar uma postura "irônica", quer dizer, a daqueles que ao menos sabem que nada sabem ou podem saber com certeza. Postura responsável, talvez, pela incapacidade última de transformar a "crítica da representação" e o anúncio do caráter inevitavelmente ficcional da etnografia em um novo começo para a antropologia. Afinal, como escreveu o autor nigeriano Chinua Achebe, embora toda "ficção seja indubitavelmente fictícia, ela também pode ser verdadeira ou falsa, não com a verdade ou a falsidade de um noticiário, mas em relação a sua imparcialidade, intenção, integridade" 8 .

Esse novo começo exigia reunir de forma mais consistente a crítica da representação como forma de conhecimento e forma de poder. Ou seja, exigia renunciar à representação não porqueé falsa ou ficcional, nem mesmo porqueé sempre uma relação de poder que concede a alguém o direito de representar outrem, mas sim porque a representação faz parte do conjunto de prolongamentos das relações de poder que o Ocidente capitalista estabeleceu dentro do texto antropológico com as demais sociedades do planeta9. É justamente o reconhecimento do caráter imanente das relações estabelecidas pelo poder com o texto antropológico que teria podido abrir linhas de fuga para o antropólogo escritor, uma vez que ele estaria às voltas com as relações de poder no espaço parcialmente sob seu controle, o próprio texto antropológico. Nesse sentido, teria sido possível levantar uma questão ao mesmo tempo epistemológica, ética e política: como proceder de modo a não reproduzir, no plano da produção de conhecimento 
antropológico, as relações de dominação a que os grupos com quem os antropólogos trabalham se acham submetidos?

Para isso, não era necessário ter ido muito longe. Bastaria ter conectado a crítica da antropologia enquanto representação com aquela, pouco mais antiga, que criticava o saber antropológico expondo suas relações de dependência para com o empreendimento colonialista. Não no sentido megalomaníaco que faria da antropologia um saber fundamental para o colonialismo, mas, como sustentou Talal Asad $^{10}$, no sentido em que o colonialismo é importante demais para a antropologia, obrigando-a, consequentemente, a buscar romper essa dependência política, ética e epistemológica:

A antropologia histórica espelhava a ideologia dos impérios coloniais e supra-étnicos tardios da Grã-Bretanha, da França, de países da Europa Central e outros (esses impérios quase que literalmente "fizeram" a evolução e a difusão Culturais como política pública). $A$ antropologia sistêmica refletia a urgência racional da mobilização de guerra e o Estado-nação econômico (p.231, grifos meus).

Mas se a atenção a esta relação entre escolas e conceitos antropológicos com os empreendimentos colonialistas e imperialistas (estabelecida aqui de uma forma que poderíamos qualificar de imanente ou intrínseca) demonstra, creio, o interesse de Wagner na questão levantada por Asad, o trecho que se segue mostra que a linha de fuga por ele traçada segue uma trajetória bem diferente daquela esboçada na coletânea organizada pelo segundo ${ }^{11}$ :

A curiosa "evolução" através da qual cada um dos sucessivos episódios paradigmáticos conduziu a simesmo no sentido da obviação e contradição de seus pressupostos originais fornece a evidência mais convincente da natureza da antropologia como disciplina acadêmica. Trata-se de uma ação de contenção contra a relatividade, uma espécie de fixativo teórico que erige insight introspectivo em teoria culturalmente corroborativa (pp.231-232).

Wagner aposta, pois, na radicalização do poder subversivo da prática etnográfica da antropologia - e não na análise das próprias relações entre a antropologia e o colonialismo ou o imperialismo como meio capaz de romper com a dependência da primeira em face dos segundos.

Nesse sentido, o problema central do pós-modernismo antropológico, como Wagner mostrou em uma resenha pouco conhecida que escreveu sobre Writing culture ${ }^{12}$,é a pretensão de "fazer com a etnografia o que uma antropologia mais segura de si e menos cínica (a 'Grande Teoria', como se diz) fez com a teoria - desenvolver poderosos e deci-
[10] Asad, Talal. "From the history of colonial anthropology to the anthropology of western hegemony". In: Stocking Jr., George W. (org.). PostColonial situations: essays in the contextualization of ethnographic knowledge. Madison: University of Wisconsin Press, pp. 314-24, p.315.

[11] Idem (org.). Anthropology and the colonial encounter. Nova York: Humanities, 1973

[12] Wagner,R. "The theater of factand its critics". Anthropological Quarterly, vol. $59, \mathrm{n}^{\circ} 2,1986, \mathrm{pp} .97-9, \mathrm{p} .99$. 
[13] Deleuze, G. e Guattari, F. Qu'estce que la philosophie? Paris: Minuit, 1991, pp. 8-10.

\begin{abstract}
[14] Para um cuidadoso estudo sobre as possíveis relações entre os pensamentos de Wagner (além de Marilyn Strathern e Bruno Latour), de um lado, Deleuze e Guattari, de outro, ver Viveiros de Castro, E. "Filiação intensiva e aliança demoníaca". Novos Estudos Cebrap, vol. 77, 2007, pp. 91-126.
\end{abstract}

[15] Deleuze e Guattari. Mille plateaux. Paris: Minuit, 1980, p. 457.

[16] Strathern, M. The gender of the gift: problems with women and problems with society in Melanesia. Berkeley: University of California Press, 1988, pp.18-19, passim. sivos cânones de compreensão". Ou seja, introjetar na própria etnografia os mecanismos de controle em geral empregados pela teoria. Assim, se o antropólogo tradicional opera como uma espécie de crítico do fato - no sentido do crítico de arte que tenta mostrar que, por maior que seja a novidade aparente do que está sendo apresentado, "tudo já foi dito antes" (p. 235) e na verdade não está acontecendo nada -, o antropólogo pós-moderno pode ser entendido como o crítico de um "teatro do fato", utilizado a "autoridade" ("a peça dentro da peça", como a define Wagner) como meio de controle adicional. Nem as ideias, nem os fatos devem ter o poder de espantar ninguém!

Para traçar essa linha de fuga, Wagner foi obrigado, em primeiro lugar, a redefinir, ou a redirecionar, tanto a noção de invenção como a de cultura. É por isso que cada palavra do título deste livro incluindo o artigo e a preposição - são fundamentais e devem ser bem compreendidas. Para começar, o que significa "invenção" em $A$ invenção da cultura?

No início de O que é a filosofia, Deleuze e Guattari³, após definirem provisoriamente essa atividade como "a arte de formar, de inventar, de fabricar conceitos", e de argumentarem que os conceitos, na verdade, "não são necessariamente formas, achados ou produtos", concluem que "a filosofia, mais rigorosamente, é a disciplina que consiste em criar conceitos". Eu arriscaria dizer que no livro de Wagner a noção de invenção deve ser entendida rigorosamente no sentido estabelecido por Deleuze e Guattari para a noção de criação ${ }^{14}$.

Isso significa que a "invenção" de Wagner não consiste nem na imposição de uma forma ativa externa a uma matéria inerte, nem da descoberta de uma pura novidade, nem na fabricação de um produto final a partir de uma matéria-prima qualquer.Isso a afasta dos modelos mais recorrentes utilizados no Ocidente para pensar o ato de criação: o modelo hilemórfico grego ${ }^{15}$, o judaico-cristão da criação ex nihilo, o modelo capitalista de produção e da propriedade ${ }^{16}$. A invenção wagneriana é, antes, da ordem da metamorfose contínua, como acontece na imensa maioria das cosmogonias estudadas pelos antropólogos, em que as forças, o mundo e os seres são sempre criados e recriados a partir de algo preexistente. Ponto que acarreta uma série de consequências.

A primeira é o fato de que esse conceito de invenção-criação tem mais a ver com arte do que com ciência e técnicas. Não é por acaso que a pintura de Bruegel, Rembrandt, Rubens e Vermeer, a poesia de Morgenstern e Rilke, a música de Beethoven, Haydn, Mozart e o jazz aparecem ao longo do livro como meios de explicação da atividade do antropólogo. Pois esta atividadeé definida justamente em termos de sua criatividade, termo que gera o título do segundo capítulo ("A cultura como criatividade") e que aparece, direta ou correlatamente, mais de cem vezes ao longo do texto. A particularidade da antro- 
pologia é que a criatividade do antropólogo depende de outra (e de outrem): aquela das pessoas com quem escolheu conviver durante um período de sua vida. Aqui tocamos num ponto fundamental, pois o reconhecimento da criatividade daqueles que "estudam" é, para Wagner, condição de possibilidade da prática antropológica. Mais do que isso, o antropólogo deve estar preparado e disposto a assumir duas premissas: reconhecer naqueles que estuda o mesmo nível de criatividade que crê possuir; não assimilar a forma, ou o "estilo", de criatividade que encontra no campo com aquele com o qual está acostumado e que ele próprio pratica.

Wagner é, assim, o primeiro a propor um verdadeiro construtivismo para a antropologia. $\mathrm{Ou}$, pelo menos, a elaborar o acabamento daquele há muito estabelecido por Malinowski ao anunciar o trabalho de campo como o único procedimento adequado para a antropologia então "moderna". Foi ainda em 1935 que ele sustentou que esse trabalho de campo seria, sobretudo, uma atividade construtiva ou criativa, uma vez que os fatos etnográficos "não existem", sendo preciso, portanto, um "método para a descoberta de fatos invisíveis por meio da inferência construtiva” 17 - posição que, infelizmente, não parece ter tido muito eco ao longo da história da disciplina.

A esse respeito, mais uma vez, é preciso atenção. O construtivismo wagneriano (e já o malinowskiano) tem pouco ou nada a ver com a ladainha pseudo politizadora do famigerado construcionismo social. Este, como se sabe, dedica-se a afirmar o caráter "socialmente construído" do que quer que seja (das relações de parentesco aos genes e planetas), mas concede um estranho direito de exceção a seus próprios procedimentos, bem como àquilo a que atribui o papel de grande arquiteto, a saber, as relações sociais e políticas que apenas o analista tem a miraculosa capacidade de enxergar. Assim, não pode haver dúvidas de que os agentes sociais passam todo seu tempo construindo, mas, infelizmente, não são capazes de perceber que estão construindo, "naturalizando" e "essencializando", como se diz, tudo o que pensam encontrar pelo caminho, mas que, na verdade, foram eles mesmos que fizeram. Cabe ao analista, então, "desconstruir" essas ilusões, o que faz com que, estranhamente, construcionismo social e desconstrucionismo queiram dizer exatamente a mesma coisa. Durkheim ao menos sabia o que é essa "sociedade" que tudo cria mas que é, ela própria, incriada: Deus - e nada poderia ser mais diferente da ideia de uma invenção criativa da cultura. É por isso, aliás, que "trabalho de campo é trabalho no campo" (p.49).

No entanto, há os que pensam que a posição de Wagner coincide com esse fetichismo generalizado do qual apenas o antropólogo está isento, essa espécie de "criacionismo de pobre", como o definiu Latour ${ }^{18}$. O problema é que quando se supõe que a cultura a ser estu-
[17] Malinowski, B.Coralgardensand their magic. Londres: George Allen \& Unwin, 1935, vol. 1, p. 317.

[18] Latour, B. Petite réflexion sur le culte moderne des dieux faitiches. Paris: Synthélabo, 1996, p.101. 
[19] Como escreveu Marilyn Strathern, "etnografias são construções analíticas de acadêmicos; os povos que eles estudam não. Faz parte do exercício antropológico reconhecer que a criatividade desses povos é maior do que o que pode ser compreendido por qualquer análise" (op.cit., p.XII).
[20] "A monotonia que encontramos em escolas de missão, em campos de refugiados e às vezes em aldeias aculturadas' é sintomática não da ausência de 'Cultura', mas da ausência de sua própria antítese - aquela 'magia', aquela imagem insolente de ousadia e invenção que faz cultura, precipitando suas regularidades na medida em que falha em superá-las por completo" (p. 146). Ou seja, o que falta nesses lugares é vida, e o antropólogo deveria falar em desvitalização no lugar de aculturação. dada pelo antropólogo é "socialmente construída", não apenas "a invenção da cultura" se torna uma "invencionice" como, por vezes, os próprios nativos passam por ter sido "socialmente construídos" por um antropólogo interesseiro' ${ }^{19}$. Para isso, claro, é preciso imaginar um "nativo-em-si" (por exemplo, os Daribi das Terras Altas da Papua Nova Guiné, que Wagner estudou, ou os Bororo do Brasil Central) absolutamente impenetrável para a nossa compreensão a qual, não obstante, se torna surpreendentemente poderosa e clarividente quando se trata de determinar os verdadeiros motivos e causas sociais e políticas que levaram o antropólogo a "construir" os nativos desta ou daquela forma.

Wagner, no entanto, jamais afirma que o antropólogo inventa a cultura, porque não há nada para ver ou porque é incapaz de compreender o que pensa que vê. O problema é outro, é que há coisas demais para serem vistas, ideias demais para serem compreendidas e muito pouco tempo para fazê-lo. O antropólogo faz o que pode, inventando a cultura para tentar conferir um mínimo de ordem e inteligibilidade lá onde a plenitude da vida as dispensa completamente. Nesse sentido, Wagner é provavelmente o primeiro antropólogo a fazer da vida (e não da evolução, história, função, estrutura, cognição...) o referente último do trabalho antropológico. Além de fundar o construtivismo em antropologia, ele também funda uma espécie de vitalismo antropológico ${ }^{20}$.

O construtivismo, no entanto, só pode funcionar se for completo e generalizado, e a obrigação do antropólogo é que sua criação faça aparecer a criatividade da qual ela mesma depende (a sua própria)e, principalmente, a das pessoas com quem trabalha. Ele se assemelha, assim, a um desses demiurgos das mitologias que estuda, aqueles que criam um mundo lá onde outro mundo já existia e sempre existiu. Nesse processo, há duas tentações às quais deve resistir: imaginar que está apenas "representando" o que existe em si e por si mesmo; pretender estar criando a partir do nada.

Em ambos os casos a criatividade daqueles que estudamos é recusada. No primeiro - que corresponde, grosso modo, às antropologias que Wagner designa como "diacrônica" ou "histórica" e "sincrônicas" ou "sistêmicas" (p. 230) -, essa recusa se disfarça sob uma aparente afirmação. Afinal, se os antropólogos nada fazem além de representar as outras culturas, apenas as pessoas que aí vivem podem ser as responsáveis por elas. O problema é que essas antropologias só afirmam tal criatividade para negá-la, ao atribuírem papel determinante a forças que as pessoas não conhecem e não controlam: evolução, ordem, função, sentido, inconsciente ou o que quer que seja. No segundo caso que corresponde mais ou menos aos pós-modernismos, construcionismos e desconstrucionismos dos últimos anos - estaríamos às 
voltas com uma recusa ainda mais absoluta: a criatividade nativa é vista como uma espécie de quimera à qual simplesmente não podemos ter acesso. Inconscientes num caso, incognoscíveis no outro, o papel dos nativos é servir de modelo para um academicismo ${ }^{21} \mathrm{da}$ representação ou de pretexto para um pessimismo da ficção. Ambos nos livram de todos os riscos, nos deixam intactos e incólumes, mas, ao mesmo tempo, incapazes de sermos afetados, modificados, ou seja, impossibilitados de pensar:

O passo crucial - que é simultaneamente ético e teórico - consiste em permanecer fiel às implicações de nossa pressuposição da cultura. Se nossa cultura é criativa, então as "culturas" que estudamos, assim como outros casos desse fenômeno, também têm de sê-lo. Pois toda vez que fazemos com que outros se tornem parte de uma "realidade" que inventamos sozinhos, negando-lhes sua criatividade ao usurpar seu direito de criar, usamos essas pessoas e seu modo de vida e as tornamos subservientes a nós (p.46).

Se a criatividade é um fenômenos geral, ainda que se manifeste sempre sob determinados estilos, o antropólogo lida com um tipo particular de invenção, a "da cultura". Em 1975, não seria difícil dizer da cultura o que Descartes dizia do bom senso: queé a coisa mais bem dividida do mundo ${ }^{22}$. A invenção, por outro lado, parecia privilégio de poucos (nós mesmos, na verdade). Trinta e cinco anos depois, as coisas parecem ter se modificado. A invenção, no mau sentido da palavra, claro, parece estar em toda parte, e a cultura (ou a tradição) só existe porque é uma invenção de nativos e/ou de antropólogos defendendo seus próprios interesses.

De certo modo, Wagner já havia invertido o quadro. É a invenção, no bom sentido de criatividade, que constitui o plano de consistência de todos os humanos (e talvez não só deles); a invenção da cultura, por outro lado, corresponde a um episódio histórico (cultural) muito específico, ocorrido em certo momento da história do mundo ocidental. É nesse sentido que poderíamos dizer que Wagner elabora uma noção de cultura propriamente cultural, ao estabelecer que dela faz parte intrínseca e constitutiva a explicitação de que a noção de cultura é ela mesma um artefato cultural, ou seja, produto de um ponto de vista cultural específico - o nosso.

O ponto fundamental, contudo, é que a origem "ocidental" da noção não é um atestado de impotência ou malignidade, mas apenas o signo de um trabalho a ser continuamente realizado. Assim, que nossa noção de cultura derive da de "cultivo" e que, mais tarde, tenha recebido seu sentido "sala de ópera" (pp.53-4), só se torna um problema quando interrompemos o processo de derivação ou "metaforização" (p. 54), literalizando um sentido que é sempre local, transitório
[21] Que, como se sabe, corresponde a um estilo pautado unicamente pelo esforço de manter com rigor intransigente as regras e as técnicas das academias de formação. Qualquer semelhança com a antropologia contemporânea não é mera coincidência (ver p. 228).

[22] Ver Strathern, "The nice thing about culture is that everyone has it". In: Shifting contexts: transformations in anthropological knowledge. Londres, Routledge, pp. 153-76,1995. 
[23] A alternativa seria o silêncio ou a autocontemplação. Como escreveu Strathern, "o fato de não existir lugar fora de uma cultura exceto em outras culturas" levanta um problema "técnico: como criar uma consciência de mundos sociais diferentes quando tudo o que se tem à disposição são termos que pertencem ao nosso mundo" ("Out of context: the persuasive fictions of anthropology". Current Anthropology, vol. 28, $\mathrm{n}^{\circ} 3$, 1987, pp. 251-281, p. 256).

[24] Schneider, D.American kinship: a cultural account. New Jersey: PrenticeHall, 1968. e instável. Cada um pensa e fala com as palavras e as categorias de que dispõe, e a grande questão é como proceder de modo que elas sejam capazes de dizer mais, ou outra coisa, do que o de costume, mantendo, não obstante, sua inteligibilidade ${ }^{23}$.

Aqui devemos retroceder um pouco. O brevíssimo quadro da moderna antropologia culturalista norte-americana esboçado no início desta resenha deixou intencionalmente de fora aquele que é certamente a mais importante "influência" sobre Wagner, seu orientador no doutorado David Schneider, a quem $A$ invenção da cultura é dedicado.Ao lado de Geertz e Sahlins, Schneider completa a trinca de autores que de algum modo acabam (no duplo sentido da palavra) o culturalismo antropológico. Ora, o ponto fundamental do principal trabalho de Schneider ${ }^{24}$ - e nisso reside, creio, sua originalidade em relação a todos os demais culturalistas - consiste em sustentar que ainda que seja inevitável investigar outras culturas a partir de categorias da nossa (o parentesco, no caso), isso não pode nos fazer imaginar que nossas categorias sejam universais. Assim, e ao contrário do que muitos imaginam, não creio que o livro de Schneider simplesmente condene o estudo antropológico do parentesco por ser este, afinal, uma "categoria ocidental" (qual não seria?). Trata-se, antes, de utilizar o parentesco de um modo que Wagner designará por "analógico" (ver, por exemplo, pp. 41-45). É nesse sentido que $A$ invenção da cultura pode ser lido como uma extensão da proposta de Schneider: por que nos determos no parentesco uma vez que a própria noção de cultura também é exclusivamente "nossa"?

Mais uma vez, isso não significa condenar a antropologia por ser um empreendimento ocidental. Ela certamente o é, mas a questão éo que se pode fazer a partir dessa constatação. Assim, vimos que a noção de cultura como cultivo foi analogicamente estendida à de cultura "sala de ópera", o que permite imaginar que a noção antropológica de cultura consiste numa nova extensão analógica:

O uso antropológico de "cultura" constitui uma metaforização ulterior, se não uma democratização, dessa acepção essencialmente elitista e aristocrática. Ele equivale a uma extensão abstrata da noção de domesticação e refinamento humanos do indivíduo para o coletivo, de modo que podemos falar de cultura como controle, refinamento e aperfeiçoamento gerais do homem por ele mesmo, em lugar da conspicuidade de um só homem nesse aspecto (p.54).

Um dos argumentos centrais subjacentes em $A$ invenção da cultura é que tanto as mudanças históricas (como as que os críticos da antropologia colonial enfatizavam) como as teóricas (de que tanto gostavam os pós-modernos) exigem uma nova extensão do conceito de cultura, 
extensão que seja capaz de conectá-lo como de invenção-criação, reconhecendo assim nas "culturas" uma criatividade cuja universalidade, no entanto, não possa apagar as singularidades dos estilos locais.

Esse mecanismo de extensão do significado é o que Wagner denomina metáfora, alegoria ou, mais usualmente, analogia, e corresponde, também, à "diferenciação". O procedimento analógico deve obedecer a três princípios fundamentais. Primeiro, só pode operar num campo de diferenças, o que significa que, evidentemente, só precisamos de analogias quando nos defrontamos com situações à primeira vista irredutíveis às que nos são habituais - ou seja, analogia não é sinônimo de semelhança. Em segundo lugar, nenhum dos dois termos colocados em relação pela analogia deve estar situado em um plano superior ao outro, como se o primeiro fosse capaz de revelar a verdade oculta do segundo - analogia não significa explicação. Por fim, os dois termos devem ser afetados pelo processo, de tal modo que o conceito ocidental de cultura, por exemplo, tem que ser ao menos ligeiramente subvertido quando serve de analogia para a vida nativa - o que significa que a analogia é da ordem da relação: "a ideia de 'relação' é importante aqui pois é mais apropriada à conciliação de duas entidades ou pontos de vista equivalentes do que noções como 'análise' ou 'exame', com suas pretensões de objetividade absoluta" (p.29).

É nesse sentido que a cultura só pode ser inventada em situações de "choque cultural" (p.34), choque que, paradoxalmente, preexiste à própria cultura; e é por isso, também, que "todo ser humano é um 'antropólogo', um inventor de cultura" (p.76) em situações de ininteligibilidade primeira. Isso significa, ao mesmo tempo - ponto importante a fim de evitar a tradicional húbris antropológica -, que todo antropólogo é apenas um ser humano, operando em condições mais ou menos especiais. Ao contrário da nossa tradicional pretensão, o máximo a que o podemos almejaréviverem dois (ou mais) mundos ou modos de vida diferentes, mas não entre as culturas, como se fôssemos capazes de transcendê-las:

Assim é que gradualmente, no curso do trabalho de campo, ele próprio se torna o elo entre culturas por força de sua vivência em ambas; é é esse "conhecimento" e essa competência que ele mobiliza ao descrever e explicar a cultura estudada. "Cultura", nesse sentido, traça um sinal de igualdade invisivel entre o conhecedor (que vem a conhecer a si próprio) e o conhecido (que constitui uma comunidade de conhecedores) (p.30).

É por isso, enfim, que o estatuto da noção de cultura ao longo de A invenção da cultura é muito complexo, uma vez que Wagner parece defini-lo de diferentes modos ou, para ser mais preciso, encará-lo de diferentes ângulos. Ele aparece ora em sentido forte, ora em sentido fraco, 
o que não significa, de modo algum, que o primeiro seja melhor que o segundo. A "cultura" começa sendo definida como o que todo mundo tem; depois, como o que só nós temos e que os outros só têm porque nós a colocamos lá; mais tarde como aquilo que ninguém tem; e, por fim, como aquilo que todo mundo tem porque a cria em situações relacionais específicas. Nos termos do próprio Wagner, a cultura começa como dada e passa para a ordem do feito - primeiro como falsa invenção e depois, enfim, como invenção-criação.

Passemos, então, ao "da", que separa "invenção" e "cultura”. Nossos hábitos acadêmicos são tão arraigados que podem nos fazer imaginar que esse partícula poderia significar apenas queé a cultura queéinventada. Se isso fosse verdade, contudo, todo o livro perderia o sentido, pois seu ponto central é justamente mostrar que a invenção da cultura é inseparável daquilo que a cultura inventa. A cultura "inventada" corresponde, basicamente, ao que Wagner denomina "convenção"; a cultura "inventante" ao que ele chama de "diferenciação" — talvez os conceitos centrais do livro.

Convenção e diferenciação constituem, em primeiro lugar, os dois mecanismos básicos da semiótica particular adotada por Wagner. Nesse sentido, ponto crucial, não constituem dois "tipos" de coisas, mas as duas faces da mesma realidade (ver p. 88). Simbolizar é sempre utilizar de forma "diferenciada" símbolos que fazem parte de uma "convenção", e é apenas o peso respectivo de cada procedimento em cada ato simbólico que varia. É por isso que "a distinção [é] mais complicada do que dicotomias simplistas do tipo 'progressista-conservador', apropriadamente parodiadas por Marshall Sahlins na expressão 'the West and the Rest"' (p.16).

Por outro lado, quando nós confrontamos nossa própria cultura ou, para ser mais preciso, a "moderna cultura interpretativa norte-americana", com os Daribi - ou com qualquer conjunto que Wagner designa alternadamente com combinações dos substantivos classes, grupos, povos, sociedades, tradições, e dos adjetivos camponeses, trabalhadoras, étnicas, não racionalistas, religiosos, tribais - nós temos a sensação que o investimento no convencional e no diferenciante muda de lugar. Assim, tendemos a imaginar que nossas regras são puramente convencionais, aquilo que fazemos e, consequentemente, o domínio que está sob nossa responsabilidade (p. 19) e onde investiremos nossa criatividade. Mas os Daribi e muitos outros parecem imaginar o contrário, a saber, que este reino, para nós convencional e feito,é da ordem do dado.Até aí, convenhamos, não há muita novidade: a imagem de primitivos vivendo sob o império de uma tradição que consideram transcendente é muito antiga. O que faz de Roy Wagner o mais original dos antropólogos desde Lévi-Strauss é ter colocado a questão que faltava: onde, então, esses "primitivos" investem sua 
criatividade? Num enorme esforço para se singularizar diante de uma convenção dada, é a resposta.

Isso traz enormes consequências. Enquanto o Ocidente foi construindo, ao longo dos séculos, a hipótese (que toma como dado) de uma natureza "lá fora" e, no entanto, controlável (p. 225), os Daribi, os Bororo e outros parecem preferir o “'mundo como hipótese', que nunca se submete às exigências rigorosas da 'prova' ou legitimação final, um mundo não científico" (p. 171). Mas, de novo, não há necessidade de querer enxergar aqui mais um grande divisor:

O homem é tantas coisas que se fica tentado a apresentá-lo em trajes particularmente bizarros, só para mostrar o que ele é capaz de fazer [...]. E no entanto tudo o que ele é ele também não é, pois sua mais constante natureza nãoé a de ser, mas a de devir (pp.212-3).

Tudo isso pode parecer meio estranho, mas é, na verdade, bem simples. A "improvisação", define o Dictionnaire encyclopédique de la musique 25 , é a "execução musical criada na medida em que é tocada", ou "a composição ou performance livre inesperada de uma passagem musical, em geral de acordo com certas normas estilísticas mas livre das características prescritivas de um texto musical específico", como prefere a Britannica. Se nós, "de forma consciente e intencional, 'fazemos' a distinção entre o que é inato e o que é artificial ao articular os controles de uma Cultura coletiva, convencional", "o que dizer daqueles povos que convencionalmente 'fazem' o particular e o incidental, cujas vidas parecem ser uma espécie de improvisação contínua?" (pp. 142-3), e onde os controles

[... não são Cultura; não são pensados para serem "executados" ou seguidos como um "código", mas para serem usados como a base da improvisação inventiva [...]. Os controles são temas para interpretação e variação - um pouco ao modo do jazz, que vive da constante improvisação de seu tema (pp.144-5).

A aproximação com a música permite levantar, ainda, três pontos complementares. Primeiro, nem tudo é permitido, e as improvisações têm que ser levadas a sério pelos outros, ou seja, não podem perder suas relações com a convenção. Pois elas também podem se tornar, como exclamou o grande pianista de jazz Thelonius Monk ao interromper uma sessão de improvisação, wrong mistakes (ver p. 139, para os "erros necessários" para a invenção da personalidade). Segundo, o fato de que tanto a noção de estilo como a de interpretação devem ser entendidas, em Wagner, mais no sentido musical do que culturalista ou hermenêutico dos termos. Um bom músico é capaz de tocar em
[25] P. Griffiths. "Improvisation".In: D. Arnold, Dictionnaire encyclopédique de la musique. Paris: Robert Lafont, 1988. 
[26] Como escreveu Strathern, "a interpretação deve manter estáveis os objetos de reflexão pelo tempo suficiente para que possam ser úteis" ("Cutting the network". Journal of the Royal Anthropological Institute, vol. 2, $\mathrm{n}^{\circ} 3,1996, \mathrm{pp} \cdot 517-35, \mathrm{p} \cdot 522$ ). mais de um estilo e de "interpretar" uma obra de diferentes maneiras. A "oposição" entre culturas convencionais e diferenciantes, ou entre os norte-americanos e os daribi, serve apenas para estabilizar provisoriamente a tensão dialética existente em todo processo de simbolização, e só deve ser sustentada enquanto rende alguma coisa. Mas ela também pode ser estabilizada no interior de uma cultura, de um indivíduo ou de um ato simbólico singular se isso for interessante $e^{26}$.

Por fim, é curioso que, em inglês, improvisation também se diga extemporization, que, em português, nos leva a "extemporâneo" e "intempestivo", quer dizer, a Nietzsche. Não é à toa que as últimas palavras de A invenção a cultura — "demasiado humana" — sejam deste autor, citado apenas mais uma vez no livro (pp.141). Há alguma coisa no pensamento de Nietzsche sobre a cultura como máquina de repressão da vida, e sobre a criatividade como única forma de escapar disso, que ecoa no livro de Wagner. Claro que este, antropólogo, adverte para o fato de que é a antropologia que pode funcionar como máquina de repressão na medida em que converte a vida em cultura. Se essa conversão é inevitável - uma vez que o antropólogo precisa dela para tornar a vida que escolheu viver entre outras pessoas vivível, e, depois, inteligível - , cabe a ele inventar uma noção de cultura que combata ativamente sua pulsão repressora. Questão que não pode ser resolvida de uma vez por todas e que, por isso, nos obriga a estarmos sempre às voltas com ela. Nesse sentido, o livro poderia se chamar "Diferenciação da convencionalização" — ou vice-versa!

Para terminar com o título, resta o pequeno artigo definido "a" mas mesmo eleé fundamental. Na sua ausência, o título poderia sugerir uma generalidade do processo de invenção que Wagner pretende a todo custo evitar. $\mathrm{O}$ "a" responde justamente pelo caráter abstrato do conceito de invenção da cultura, mas abstrato no sentido preciso de que apenas assinala uma condição que pode ser preenchida de diferentes maneiras, uma vez que cada invenção é sempre efetuada de acordo com um estilo particular:

E porque a percepção e a compreensão dos outros só podem proceder mediante uma espécie de analogia, conhecendo-os por meio de uma extensão do familiar, cada estilo de criatividade é também um estilo de entendimento (p.61).

É nessa chave que deve ser entendido o capital trecho acerca do que Wagner denomina "antropologia reversa" (pp. 67-72), que ele ilustra com o exemplo do culto da carga melanésio. Trata-se, de um lado, de imaginar simetricamente a literalização das "metáforas da civilização industrial moderna do ponto de vista das sociedades tribais" (p. 69); e, de outro, de entender esse "gênero pragmático de 
antropologia" (p. 71) - uma vez que ele evidentemente não assumirá a forma de uma disciplina acadêmica, constituindo, antes, um análogo desta - no sentido em que se fala de "engenharia reversa". Ou seja, da desmontagem de uma caixa-preta (no caso, a própria antropologia que praticamos) não apenas no intuito de desvendar seus mecanismos de funcionamento, mas, principalmente, de se tornar capaz de reconstituí-los. Em suma, a antropologia reversa praticada por outras sociedades explicita para nós os mecanismos que empregamos de forma implícita e, às vezes, inconfessável ${ }^{27}$.

Para concluir, poderíamos dizer que $A$ invenção da cultura segue seus próprios pressupostos em um grau muito superior à maioria das obras. O livro é percorrido por uma série de contrastes dialéticos que o autor tem o cuidado de definir como parte de uma dialética que não almeja qualquer síntese (p.96): contraste entre concepções de cultura (cap.2), modos de simbolização (cap.3), formas de subjetividade (cap.4), estilos de socialidade (cap.5), teorias antropológicas (cap.6), entre outros. A ideia de síntese parece ser uma das grandes ameaças ao pensamento isoladas por Wagner. Afinal, a pretensão às grandes sínteses - ou a denúncia das falsas, tanto faz - é apenas uma "estratégia de 'proteger a antropologia de si mesma'” (p. 227), defendendo-a da relatividade que ela mesmo revela quando é capaz de "analisar a motivação humana em um nível radical" (p.13). O primeiro capítulo do livro elabora justamente essa distância que separa a relatividade ameaçadora que a antropologia revela do "relativismo" que professa, relativismo queéa primeira forma de controle da própria relatividade, uma vez que, como escreveu Roland Barthes, "logo se detém no coração inalterável das coisas:é uma segurança, não uma perturbação" 28 . Para um espírito mais sisudo, "o fim da antropologia sintética" (p. 229), ou do "sintesismo" (234), com que Wagner encerra o livro, bem poderia ser entendido como o fim da própria antropologia. Mas, como a $A$ invenção da cultura não se cansa de demonstrar, todo fim é a ocasião da invenção de um novo começo. Creio que nisso consiste a aposta de Roy Wagner.

Espero que o Wagner que inventei seja suficientemente flexível para escapar de uma convencionalização demasiado rápida. Porque ninguém precisa se iludir: mesmo autores tão criativos quando ele não deixam de ser incessantemente "contrainventados" na forma convencional de algo como um neo-Durkheim, cujos conceitos e ideias seriam capazes de dar conta do que quer que seja e a quem devemos devoção respeitosa. Antes de "aplicá-lo" ali e acolá, convém meditar sobre a nova forma de conexão entre fatos e teorias que pensamentos como o de Wagner nos convidam a imaginar. Certamente, coisas e ideias não são nem a mesma coisa — nem a mesma ideia. Mas isso
[27] "Nessa situação, a antropologia não pode permitir-se o papel de Grande Inquisidor" (p.236). [28] Barthes, R. "De um lado e do
outro". In: Crítica e verdade. São
Paulo: Perspectiva, 1970 [1961], pp.
139-47, pp.139-40. 
não significa que as relações entre elas sejam da ordem da hierarquia vertical, com umas, não importa quais, sendo mais importantes do que as outras. Sua relação, como diria Guattari, é transversal; para um antropólogo, a questão é como traçar transversalmente as relações entre o que aprendeu na academia e aquilo que viu e que seus amigos lhe ensinaram no campo. Só assim, creio, poderemos responder com um "não" definitivo quando nossos amigos levantarem a questão que os daribi propuseram a Wagner: "vocês antropólogos, podem se casar com gente do governo e com missionários?".

MARCio Goldman é Professor Associado do Programa de Pós-Graduação em Antropologia Social, Museu Nacional, Universidade Federal do Rio de Janeiro e pesquisador do CNPq e da Faperj. 